\title{
Jornada de Bioética em Assistência ONCOLÓgICA
}

\author{
Symposium of Bioethics in Oncologic Care
}

\author{
Fermin Roland Schramm', Emilia Rebelo Pinto ${ }^{2}$, Maria Inez \\ Pordeus Gadelha ${ }^{3}$, Maria Alice Sigaud ${ }^{4}$, Euclydes Arreguy ${ }^{5}$
}

\section{Introdução}

A bioética é uma das mais importantes formas de ética aplicada da atualidade para analisar e ponderar conflitos de interesses e valores que surgem no encontro entre médico (ou prestador de serviços) e paciente (ou usuário dos mesmos). Em sua dimensão prática, resulta da cooperação entre médicos, outros profissionais em saúde e especialistas em ciências humanas e sociais, inclusive filósofos e teólogos, a princípio todos preocupados em resolver os dilemas morais advindos do campo da assistência em saúde.

Os dilemas surgem devido a conflitos de interesses, resultantes essencialmente de políticas públicas de alocação de recursos em situação de escassez, concepções contrastantes sobre prioridades sanitárias e "visões de mundo" diferentes sobre o que pode ou deve ser considerado o D esejável, o Bem/Bom e o Justo.

Tudo isto tornado possível e legítimo ao longo do processo de secularização e democratização das sociedades ocidentais.

0 estudo de casos cujas peculiaridades transcendem a decisão da equipe médica constitui um momento importantenão só para os profissionais em saúde, mas também para os demais profissionais, tais como filósofos, teólogos, juristas e jornalistas, assim como para representantes governamentais e de organizações não governamentais, gestores, representantes de usuários, devido ao caráter

I J ornada deBioética em Assisência O ncológica. Realizada pelo C onselho de Bioética do I N CA em 9 demaio de2000, no H ospital do Câncer I, da Praça da Cruz Vermelha.

1- D outor em Ciências. Sanitarista eBioeticista. Presidentedo C onselho de Bioética do Instituto N acional de Câncer - IN CA

2- M édica, Assessora de G abinetedo Instituto N acional deCâncer - IN CA eminentemente problemático que, muitas vezes, tais casos assumem, e que precisam portanto da cooperação interdisciplinar para tentar resolver o caso em pauta da melhor maneira ou da forma menos traumática possível.

Em particular, para os profissionais em ética aplicada e bioética, a análise destes casos constitui um momento privilegiado, pois concretiza e torna visível a preocupação em aplicar suas ferramentas conceituais e metodológicas à realidade cotidiana do hospital, vivenciada pelos médicos, suas equipes e os pacientes. M as esta aproximação entre Academia e H ospital só se torna produtiva com o diálogo aberto e franco entre concepções e teorias morais diferentes, norteado pela preocupação de defender e promover a melhor qualidade de vida possível dos principais interessados, que são também, quase sempre, os mais vulneráveis: os usuários.

A O ncologia é responsável pelo estudo de procedimentos aplicados a um grupo de doenças com a segunda maior taxa de mortalidade do país (só superada pelas doenças cardiovasculares), e é de uma certa forma paradigmática, pois reúne praticamente todos os componentes que caracterizam a conflitualidade com a qual lida tanto a bioética clínica quanto a ética sanitária. Por isso, a D ireção Geral do Instituto $\mathrm{N}$ acional de Câncer (IN CA) junto com seu Conselho de

3- M édica, ChefedeG abinete do Instituto N acional deCâncer - IN CA

4- Coordenadora deEnsino eD ivulgação Científica do Instituto $\mathrm{N}$ acional deCâncer - IN CA

5- Gerente de Ensino e D ivulgação Científica do Instituto $\mathrm{N}$ acional de Câncer - INCA 
Bioética (ConBio), decidiu organizar esta I Jornada de Bioética em Assistência O ncológica.

A metodologia adotada pela coordenação da Jornada consistiu em apresentar sucintamente um caso clínico que pode ser considerado paradigmático da moralidade oncológica, sendo em seguida debatido por profissionais da saúde; do direito; da filosofia; da informação; representantes dos usuários e a própria platéia. Para propiciar um melhor entendimento das questões médicas envolvidas ao público externo à área da Saúde, foram ressaltadas "informações técnicas" e, apesar de ser real, o caso servia apenas para incentivar as discussões das questões bioéticas envolvidas, alvo da Jornada.

\section{Caso}

U ma mulher de 44 anos, professora, mãe de um menino de 8 anos, foi matriculada no H ospital do Câncer I do IN CA, em 17/06/ 98, com câncer da mama direita, que vinha em tratamento desde 1996. Temos aqui o primeiro equívoco, pois matrícula de doente previamente tratado transgredia as normas vigentes da instituição.

No prontuário da paciente não havia informações relevantes, tais como estadiamento e dosagem de receptores hormonais, dentre outras, para orientar o tratamento e estabelecer o prognóstico. A falta destas pode ser interpretada como perda da integralidade da assistência e do intercâmbio de informações na área da saúde.

Em 1996 a paciente foi submetida à mastectomia radical direita (retirada de toda a mama) e reconstrução imediata. Complementou com quimioterapia, hormonioterapia adjuvante e radioterapia. Permaneceu assintomática e sem evidência da doença até o início de 1998, quando apresentou recidiva do tumor em linfonodo axilar à direita, não constando informações no prontuário sobre onde e quem realizou o diagnóstico e 0 tratamento.

Ao ser admitida no $\mathrm{H}$ ospital do Câncer I do IN CA, em junho de 1998, a paciente apresentava linfoadenomegalia supraclavicular à direita.

Devido à falta de informações no prontuário, optou-se por submeter novamente a paciente a hormonioterapia e quimioterapia, com conseqüente baixa resposta. 0 esquema quimioterápico indicado consistia no uso de taxanos, uma nova classe de drogas de alto custo, recentemente incorporada pelo IN CA.

D evido a pouca resposta obtida, o pai da paciente decidiu enviar uma carta destinada a diversas autoridades, Presidente da República, M inistro da Saúde, Diretor Geral do IN CA, Secretário M unicipal de Saúde; aos jornais do Rio de Janeiro e a dois conhecidos comunicadores de televisão, com a seguinte queixa: "O IN C A não tem verba para adquirir remédio para a minha filha" e exigindo que seus direitos de cidadão, "após 35 anos de trabal ho e contribuição à Previdência", fossem respeitados, e que a filha fosse curada.

Esclarecimento: o câncer não é uma doença contagiosa, transmissível e a paciente havia recebido, e estava recebendo, o que a $M$ edicina pode, atualmente, oferecer para este tipo de doença, apesar da resposta observada. Por outro lado, a finalidade terapêutica para doença recidivada ou metastática não é mais curativa e sim paliativa.

Em dezembro de 1999, o pai da paciente escreveu uma nova carta, destinada ao Presidente da República, queixando-se de que "o IN CA não tem verba para adquirir o remédio indicado (Taxotere)", que sua filha estava morrendo "por falta do remédio" e que "seu neto passa [va] mal e pede [ia] para que a mãe não morra [esse]". 0 pai ainda fazia notar que "são muitas crianças, moços e velhos que precisam do IN CA", que a filha estava tomando o remédio "só que demora [va] 42 dias para chegar, o que faz [ia] com que a doença avance [asse]". Terminava sua carta pedindo "socorro!".

A doença da paciente evoluiu com metástase hepática, mesmo após ser submetida a 3 ciclos de Taxotere. Essa evolução era esperada, pois é característica de disseminação de câncer mamário de mau prognóstico (paciente com idade $\leq 50$ anos, receptor hormonal negativo, primeira recidiva em menos de 2 anos após o primeiro tratamento, recidiva em linfonodos supraclaviculares). Por isso, a paciente tinha sido encaminhada ao Centro de Suporte Terapêutico O ncológico - CSTO/ INCA - a unidade médico-assistencial destinada aos pacientes que foram tratados 
nas outras U nidades H ospitalares do IN CA e que estão fora de possibilidades terapêuticas, mas que precisam de cuidados paliativos.

O pai da paciente enviou então uma terceira carta ao Presidente da República, ao M inistro da Saúde e aos jornais do Rio de Janeiro com a queixa de que o IN CA estava "descartando" sua filha ao encaminhá-la a um $\mathrm{H}$ ospital de doentes terminais, e que se sentia injustiçado, depois de 35 anos de trabalho. Q ueria saber 0 que fazer com 0 neto de 8 anos, visto que sua filha, com o câncer disseminado, não podia dispensar a assistência dos especialistas do IN CA.

Esclarecimento: cuidados paliativos são condutas simples, básicas, propiciadas por médicos e outros profissionais em oncologia, e prestados em dependências hospitalares de baixa complexidade, ou em domicílio, sob orientação e supervisão regular. O s especialistas desta área trabalham em uma unidade hospitalar denominada CSTO/INCA e proporcionam à paciente assistência quanto à dieta, medicação anti-inflamatória e analgésica (inclusive opiáceo forte) e internação domiciliar assistida por equipe multiprofissional. Além disso, a internação domiciliar favorece 0 doente, que permanece em casa, junto aos seus parentes, amigos e pertences. Essa modalidade de internação conta com o treinamento apropriado de quem cuida e com a supervisão regular da equipe do CST 0 , através de visitas domiciliares agendadas. $M$ antém, ainda, um setor de ambulatórios, um setor de emergência, um serviço de orientação à distância e um setor de internação hospitalar para cobertura dos casos assistidos em domicílio.

Em fevereiro de 2000, foi enviado um mandado judicial instando ao Diretor Geral do IN CA a internação e o tratamento da doente no CSTO.

O cumprimento deste fez com que fosse cancelada a transferência de um doente em fase terminal do HC I/INCA para o CST O/ IN CA e o cancelamento de duas cirurgias eletivas, gerando várias reclamações ao $D$ isque Saúde quanto à falta de respeito ao cidadão e à desorganização do IN CA.

Em março de 2000, o pai enviou outra carta ao M inistro da Saúde solicitando a importação de uma vacina pesquisada no C anadá, pois teria lido a notícia que um médico do IN CA e outro em São Paulo já a estariam usando. N esse momento, a D ireção Geral do INCA solicitou uma assistência psicológica extensiva ao pai da doente, após escutar da mesma a seguinte solicitação: "Livrem-me do meu pai; quero morrer em paz!"

\section{Debate}

Debatedores

G estores de Saúde: Alberto Beltrame, Ana Ramalho

Jornalistas: Fritz U tzeri, Ancelmo Góis

Juristas: Elton Leme, Tânia $\mathrm{H}$ eine

U suárias: Sonia Leite Guimarães, G raça $M$ arques

Bioeticistas: Abrão Rapoport, 0 linto Pegoraro

\section{0 ponto de vista dos gestores de saúde}

Ana Ramalho (Coordenadora do Programa de Doenças (rônico-Degenerativas da SMS-RJ)

Um dos principais problemas do dia-dia na reorganização da assistência oncológica do Rio de Janeiro diz respeito à utilização de medicamentos. As indicações técnicas, a limitação de recursos e as demandas múltiplas para tratamento de outras doenças são fatores que dificultam a padronização destes, sem esquecer que nem sempre se pode contar com a cooperação do médico, que não quer abrir mão do medicamento que está habituado a prescrever.

Diante desta situação, surgem então as seguintes perguntas: todo medicamento novo que aparece no mercado pode ser usado ou deve ser usado? 0 que, quando, como fazer e por que fazer uso deles? Trata-se de um assunto que deve ser analisado em grupos de discussão, pois não temos soluções normativas ou respostas prontas. D e fato, na medida em que se cumpram as formalidades, o médico propõe o seu tratamento e o gestor avalia se tem recursos para comprar o medicamento.

Por que então é tão difícil implantar um sistema de atendimento? 0 paciente que sai do sistema privado porque perdeu 0 emprego ou o plano chega ao INCA já se sentindo diminuído, abandonado pelo convênio com o Sistema Privado. Ele é encaminhado a um 
protótipo de unidade que regula este fluxo de doentes, propondo-Ihe um outro local, considerado confiável, para o tratamento. $M$ as o paciente e sua família se recusam a tratar em outro local que não seja o IN CA, 0 que evidentemente levanta uma série de questões e de problemas práticos.

A principal questão, complexa e de difícil equacionamento que deve ser levada para a sociedade é se a cura é o único objetivo da medicina ou se devemos considerar as necessidades e a qualidade de vida das pessoas, os parâmetros éticos e a limitação dos recursos do sistema sanitário.

A experiência dos profissionais é um fator crucial para esta discussão.

Alberto Beltrame (Departamento de Avaliação de
Serviços de Saúde do Ministério da Saúde)

0 caso apresentado é emblemático e reflete o cotidiano do M inistério da Saúde na busca desesperada por tratamentos que nem sempre são os mais indicados e que, quase sempre, são fruto de campanha da imprensa ou de mandado judicial.

Com efeito, as distorções no sistema de saúde brasileiro tornam-se cada vez mais freqüentes: juizes prescrevendo medicamentos e a imprensa pressionando os médicos a utilizarem determinados procedimentos. Afinal, todos têm os mesmos direitos, e se tais procedimentos são feitos lá fora, devemos repeti-los aqui.

Agora, o M inistério da Saúde, como órgão normalizador e regulador, necessita que os medicamentos de alto custo sejam adequadamente prescritos e satisfaçam as condições de um programa terapêutico, com informações detalhadas. Um exemplo ilustrativo é o tratamento da $\mathrm{H}$ epatite $\mathrm{C}$ com interferon $\mathrm{e}$ outros medicamentos tóxicos, contraindicados em pacientes acima de 60 anos. 0 M inistério da Saúde recebeu um mandado judicial para que o medicamento fosse dado a um paciente de 75 anos. 0 mandado teve de ser cumprido, com evidente prejuízo para o paciente, uma vez que ele não agüentaria um tratamento com um remédio tão tóxico. Isso nos mostra a necessidade de que as áreas envolvidas se integrem, se comuniquem para que se possa chegar a soluções razoáveis.

A questão da incorporação tecnológica é outro ponto sério, uma vez que novos medicamentos, equipamentos e métodos de tratamento são veiculados pela imprensa e vendidos como milagrosos. Com efeito, 0 M inistério da Saúde sofre uma pressão muito grande de todas as partes para a incorporação desses novos meios e produtos: dos laboratórios, dos médicos, dos pesquisadores e dos pacientes. É importante que se discuta eticamente a publicação deste tipo de informação, para que se possa gerenciar tal expectativa. Por sua vez, a Justiça precisa de uma assessoria técnica para que possa advogar pelo paciente de forma justa e razoável.

o M inistério da Saúde vem sofrendo pressão para a incorporação de remédios genéricos - são milhões de reais que acabam sendo gastos, sem uma análise da relação entre custo e benefício social. Por isso, toda a sociedade precisa discutir o tema, pois nossos recursos são limitados e precisamos decidir onde eles podem ser aplicados da melhor maneira possível. Afinal até quando vamos garantir medicamentos para todos? D eve-se discutir o custo social disso e gerenciar essa situação, ou seja, avaliar com juízo "o tamanho do cobertor e o que se vai cobrir".

\section{0 ponto de vista da imprensa}

\section{Ancelmo Góis (Jornalista, Site IG)}

Em relação ao caso exposto, minha opinião é que todos os envolvidos têm razão. 0 papel do pai é aquele mesmo: espernear, gritar; o juiz fez seu dever e os médicos agiram corretamente também! 0 choque entre estes papéis faz com que haja um amadurecimento das questões, visto que o jogo democrático é que faz a sociedade avançar.

Em particular, a imprensa agiu certo porque num país onde doentes morrem por causa de água mal tratada e sofrem todo tipo de negligências é natural que haja espaço para este tipo de queixas. É verdade que a imprensa veicula muita coisa, mas as informações são passadas ao jornalista pelos médicos e por fontes renomadas. Todos os dias os noticiários falam sobre estudos internacionais - uns médicos dizem que tomar vitaminas é bom, outros dizem que é ruim, dependendo da instituição que os veicula. Fica então a pergunta: se as instituições médicas não conseguem resolver esta questão, como os jornalistas vão resolver? 
Agora, a Justiça é um problema no Brasil. A Justiça não é justa, não é igual para todos, é uma justiça de classe, uma justiça de ricos. O que falta no Brasil é um código legal para ser cumprido por todos. $M$ as os juristas devem consultar médicos, instituições, antes de deliberar uma ação ou emitir um mandado judicial. Em suma, tem que haver o diálogo.

Fritz Utzeri (Jornalista do JB com formação médica)

0 brasileiro tem um grave defeito que é 0 de citar números. Enquanto o gestor se preocupa com números e cifras, uma criança morre por falta de um medicamento ou de um tipo de atendimento. É o típico discurso do gestor versus o olhar do "homem do povo".

Em relação ao caso apresentado, acho que todo mundo tem razão e concordo com Ancelmo. N ão se deve condenar o pai, porque eu não tenho a menor idéia do que faria se um filho meu vivesse aquela situação. Em suma, o pai é um bom pai e não deve ser condenado. Agora, o IN CA falhou porque não atendeu ao pai e sim à filha. Talvez o pai precisasse mais de cuidado do que a filha. O s médicos também estão certos, mais, devido à onipotência do médico que se recusa a ver que a vida éfinita, medicaliza-se a morte e se alivia a família.

A questão dos cuidados paliativos, de se acabar com a dor, de dar conforto, de ajudar ao paciente a morrer em paz, me faz lembrar um hospital, na França, onde os pacientes terminais têm um espaço para morrer de maneira confortável, agradável.

Concordo com o Ancelmo quanto à má influência dos médicos na informação ao jornalista, mas reconheço também que existe um sensacionalismo na imprensa. Entretanto, o jornalista não sai à caça de informações médicas. Ao contrário, o jornalista é, muitas das vezes, procurado com notícias de descobertas novas para serem veiculadas.

Por outro lado, faço elogios ao IN CA porque acho que o IN CA também tem razão. A decisão tomada é efetivamente correta.

\section{0 ponto de vista dos juristas}

\author{
Elton Leme (Juiz da $3^{a}$ Vara Cível) \\ 0 profissional do direito tem semelhanças \\ com o médico, visto que ambos lidam com a
}

miséria humana, a dor física, o conflito de interesses na tomada de decisão, que podem suscitar muitas críticas.

A diferença entre $D$ eus, o médico e o juiz é que $D$ eus sabe que não é médico nem juiz. 0 jurista e o médico tentam tirar de Deus um poder que só Ele tem - curar. Agora, 0 inconformismo não é com a morte mais com a forma de morrer. A principio concordo que todos têm razão, mas o juiz deve decidir baseado em que 0 acesso à saúde é direito de todos, garantido pela Constituição. E a vida é um bem jurídico indisponível e inflexível. Assim, o juiz avalia o perigo de não se tomar uma decisão, ponderando o perigo da demora para a tomada de decisão, o direito do paciente de ter 0 atendimento, os elementos técnicos. Ademais, nenhum juiz decide sem um parecer técnico julgado competente.

Estamos diante de um conflito de procedimentos: o médico acha uma coisa, o gestor acha outra, e o juiz também. Assim sendo, não cabe ao juiz adotar uma postura mais acanhada. Ele, por precaução, adota a postura mais violenta e solta o mandado. Por princípio todos os elementos da decisão têm que estar estampados no processo, o que não é feito neste caso devido a seu caráter de emergência. Frente ao problema dos recursos finitos na medicina, para a justiça o grande problema permanece a questão humana. Só o argumento da escassez de recursos não basta, tem que se analisar o comportamento humano. 0 médico, como o juiz, não pode deixar de se sensibilizar diante de um caso concreto. Alguns defeitos que o homem comum traz consigo, um médico e um juiz também os trazem. A Justiça não é igual para todos? Ela é preconceituosa como a M edicina, que tampouco não é igual para todos. Assim sendo, para lidar com a M edicina e com a Justiça é preciso mudar o homem, pois "ao reconstruir o homem, reconstruo o mundo".

\section{Tânia Heine (Juíza do Tribunal Regional Eleitoral)}

Relação entre justiça e medicina? N ão podemos esquecer que vivemos num país de $3^{\circ}$ mundo. N os Estados Unidos, o juiz tem 150 (cento e cinqüenta) processos por ano. No Brasil, 50.000 (cinqüenta mil) processos por ano. Nos casos de crimes de "colarinho 
branco", o criminoso vai contratar os melhores advogados, assim como o paciente rico irá comprar todos os medicamentos e se tratar com os melhores médicos. Ao contrário, 0 pobre procura a $D$ efensoria Pública e 0 paciente pobre procura o IN SS. E a liminar existe para resolver casos urgentes. Portanto, todos têm razão, inclusive 0 juiz.

\section{0 ponto de vista dos representantes de usuários}

Sonia Leite (Representante dos usuários oncológicos)

Talvez vocês não saibam o que representa para nós, pacientes, ver a luta de um médico tentando achar a melhor solução de tratamento para o seu paciente. O s médicos estão sempre lutando por uma causa perdida, e isso é louvável. Eles tentam esgotar, ao máximo, todas as possibilidades.

0 paciente vai morrer, então, não vamos fazer mais nada? A questão é atender um paciente que tenha mais chance de sobrevida? Todo paciente luta pela vida. Para quem passa pelo câncer, se é falado que água benta cura, todos passam a beber. É a vontade de não morrer.

0 juiz não prescreve medicamentos. Em Petrópolis, quando um paciente recorre à Justiça para conseguir algum remédio, o juiz exige uma opinião do médico. Este é o primeiro passo para que o processo caminhe.

0 paciente só recorre à Justiça como última solução, quase sempre numa atitude desesperada ou, pelo menos, reivindicando o direito de se morrer com dignidade.

$N$ ão vi no caso exposto, e não vejo no Brasil, a preocupação de se conversar com a família, com a paciente. A informação para o paciente é fundamental, pois só assim ele poderá lidar melhor com a situação. A informação, a estrutura familiar, o grau de instrução, o apoio psicológico, fazem a diferença no tratamento e entendimento da doença. O s pacientes precisam de atenção, respeito, apoio e tratamento. Por isso, todo centro de tratamento deveria ter um suporte psicológico.

\section{0 ponto de vista dos bioeticistas}

Olinto Pegoraro (Professor de filosofia da UERJ)
0 caso apresentado suscita muitas questões sobre a vida humana. Q uero salientar alguns pontos para aprofundar a reflexão: a Bioética, entendida como ética da vida e da proteção da vida; o direito do paciente; a manipulação da vida através da Biotecnologia; são questões que temos de discutir dentro do ponto de vista ético. Como se diz, nem tudo 0 que é tecnicamente factível é eticamente conveniente de se fazer. A vida humana é mais ampla que a própria Ciência, a Filosofia e a Técnica. Portanto, nem a Ética, nem a Filosofia nem a Ciência podem, isoladamente, definir o caminho do homem.

Como gerenciar os recursos escassos? A vida é o nosso direito máximo, e inclui 0 direito à saúde. D entro do orçamento do país, isso teria que ser muito bem contemplado. Poderia haver mais recursos, se existisse uma política mais adequada. De fato, são parcas e curtas as cabeças dos que fazem o orçamento, e esta é uma questão mundial!

A apresentação do caso se refere à comunicação, à dimensão do diálogo, da informação. 0 diálogo é um dos pontos mais importantes que a Bioética trata. A paciente tinha o direito a uma informação clara, que faltou. Vivemos num país onde 0 índice cultural não é tão amplo, e nem sempre temos o sentido da vida, em relação ao:

Sentido Biológico - ter consciência de que, biologicamente, somos finitos, mesmo considerando a capacidade técnica de se prolongar a vida, o ser humano é ontologicamente finito. Se estou vivo é porque vou morrer.

Dimensão H istórica - Somos seres que fazemos a história. N este caso, a história da M edicina é uma forma de delimitar a vida. 0 ser humano vive no tempo e o tempo da vida é limitado. Todo avanço das pesquisas é bem vindo.

Transcendência - Convicção religiosa, crença em outras vidas. Faz parte da cultura, é a consciência da limitação humana.

\section{Abraão Rapoport (Membro do ConBio - INCA)}

Refletindo sobre o caso apresentado, penso que 0 juiz se defende, o jornalista se defende, a usuária fica brava e o gestor não sabe 0 que fazer. Q uando se fala de Bioética a pergunta é a seguinte: " $Q$ uantas vezes o médico se 
sentou ao lado da paciente e colocou para ela as suas limitações?". N o caso em questão, tirou-se todo o dinheiro da paciente e dos familiares e colocou-a na máquina de moer carne que é o Sistema de Saúde Pública. N ão há o que falar sobre o tratamento dado à paciente. 0 que chama atenção é a relação pai/paciente.

N este quadro, como ficamos nós, os gestores públicos? Vamos escolher quem vai viver e quem vai morrer? Há que se ter mais condições para se dar um pouquinho mais para aquele médico gastar um pouco de tempo e perguntar, discutir com o paciente 0 que ele quer, o que vai ser feito. Tenho um exemplo de um caso de um paciente que chegou com um problema no dente, esaiu do hospital com o rosto mutilado, devido a um câncer na mandíbula. Q ue informação foi dada a este paciente, se é que foi dada?

\section{Sessão de perguntas e respostas}

\section{Marilena Garcia (Pedagoga, advogada e usuária)}

Trabalho no Programa "Saúde da M ulher" do Ministério da Saúde. Sou paciente, voluntária e ex-funcionária do INCA.

No caso apresentado, três atores foram considerados: A Ciência, A Sociedade Civil (família, jornalistas, juizes) e um novo ator, o Paciente (usuário). Essa experiência do IN CA não é muito comum: ouvir o paciente, o voluntário. É muito importante existir organizações e grupos de pacientes/expacientes. 0 INCA deve contribuir para multiplicar este trabalho para influenciar as Políticas Públicas.

Existem, no Brasil, 57 grupos de ajuda mútua (voluntários) e eles apontam as falhas no Sistema de Saúde.

\section{Francisco Neves}

M eu filho morreu de câncer. Parabenizo a atitude de se reunir profissionais para se discutir o que fazer. $M$ as, o que se faz pela nossa sociedade/comunidade que, afinal, é a nossa vida?

\section{Aurélio Julião (Ribeirão Preto/SP)}

$N$ ão é apenas a informação que é importante, mas a qualidade da informação. Temos que pensar nos princípios da beneficência e não maleficência, e o respeito à autonomia do paciente.

\section{Leila Del Caro (Voluntária, ex-paciente)}

Como ex-paciente, fico estarrecida com a postura dos médicos. A classe médical jurídica deveria ter isso muito claro: a vida é um direito inalienável do ser humano. $\mathrm{M}$ as 0 momento final, o morrer dignamente, também deve ser visto.

Existe uma questão confusa quanto a não se permitir que o paciente morra com dor. M orre-se muito com dor, no Brasil. E o pior: desnecessariamente, por uma questão de preconceito. Parece que os próprios médicos nem sempre estão preparados para administrar a morfina.

\section{Sonia Leite}

O SU S não paga a morfina. E o paciente não tem condição financeira de arcar com o custo, pois cada caixa de comprimidos custa $R \$ 150,00$ e eles utilizam 6 caixas por mês.

\section{Alberto Beltrame}

A garantia da qualidade de vida do paciente terminal é extremamente importante. Existe um preconceito cultural na prescrição da morfina, devido à dependência. 0 utro tópico complicado é a dispensação e a comercialização da morfina, mas sobre a qual os Centros de Tratamento de $C$ âncer poderiam ser unidades de controle.

\section{Ana Ramalho}

Q uando se começou a reorganizar a assistência oncológica no Estado, descobriuse que a morfina oral, por exemplo, não estava padronizada. Concluiu-se que havia um certo medo em se tratar do fim da vida - quem iria prestar cuidados e como organizar os serviços de cuidados paliativos. Atualmente, as Secretarias Estaduais de Saúde estão come çando a montar estruturas para atender esta necessidade.

José Roberto Wance (Médico oncologista HC I/INCA)

Analisando a ação de cada ator (jurista, usuário, etc.), eles têm uma característica em 
comum, que é o maior benefício desta ação: 0 bem-estar do paciente.

\section{Francis Lillian da Silveira (Procuradora do Estado de Santa Catarina)}

0 papel da instituição é o mais antipático.

o Procurador do Estado está sempre tentando proteger o orçamento. Sugiro que façam informativos (folderes, cartazes) para o Judiciário, para as Procuradorias de todos os Estados, quanto aos procedimentos que são pagos pelo SUS. O maior controle irá possibilitar que se use a verba para outros fins.

Marcos Segre (Presidente da Sociedade Brasileira de Bioética)

0 grande problema da humanidade não é o câncer ou 0 H IV. É a solidão. 0 medo que vem desde sempre, desde a infância, e que quando aparece é terrível. Se há uma ameaça objetiva à vida, há o despertar daquele medo interior. 0 que se pode fazer? Dar conforto, ser solidário. É fazer o paciente não se sentir diferente ou que vai morrer antes dos outros. $D$ ar ao doente a percepção de que ele não está sozinho. 0 que consola alguém por uma perda é perceber que todos vamos morrer.

Agora, conforme ao principio da autonomia, o paciente tem o direito de saber e escolher quanto ao seu próprio destino. Se os recursos são finitos, tem-se que administrar os recursos. $\quad N$ ão se tem o poder de decisão sobre a vida/morte. $\mathrm{Na}$ alocação de recursos o homem tem o papel de D eus, em determinadas situações. Ele é quem vai decidir sobre como aplicar os recursos.

O s dois fundamentos da Bioética são: solidariedade (a empatia e a paixão) e a coragem de assumir os papéis. Coragem de abreviar a vida do paciente que quer ter a sua vida abreviada. $\mathrm{N}$ ão ter medo de descartar embriões, de assumir o seu papel social. $N$ ão há lei que consinta o aborto em gestantes com o diagnóstico de anencefalia, mas há juízes que autorizam. A ética normativa só pode resultar de normas já existentes. Cabe a nós termos coragem e assumir isso.

Se a norma não está adequada a determinado tipo de circunstância, muda-se a norma. $\mathrm{H}$ á que se tomar iniciativas, mesmo correndo alguns riscos, senão não se muda nada.

\section{Armando Raggio (Secretário Estadual de Saúde do} Paraná, Membro do ConBio)

O Governo do Paraná trabalha junto ao MS e ao IN CA para solucionar as questões levantadas pela Secretaria de Santa Catarina. Nós somos os algozes e as vítimas. Vítimas que se cumpliciam com seus algozes. É preciso ser muito otimista. 0 Brasil é um dos países de maior apartheid do mundo e que acha que isso só existe na África, mas lá já estão resolvendo isto. Abrir a discussão, praticar todos os conselhos e não desistir, tendo a grandeza e a humildade de reconhecer as limitações. 0 Brasil é muito mais do que 0 abismo que pode soterrá-lo. 0 Bem e 0 $M$ al são inseparáveis, mas podemos escolher o Bem.

\section{Abraão Rapoport (Membro do ConBio)}

Como administrar este otimismo frente um povo miserável que é excluído da maioria dos Programas?

\section{Armando Raggio}

0 otimismo é uma atitude vital. 0 pessimismo é uma atitude mortal. 0 SU S é 0 melhor pagador, pois paga os procedimentos mais complexos e de forma "religiosa", o que não acontece com os planos particulares de saúde. $\mathrm{N}$ ão é cantar em prosa e verso que 0 Brasil é maravilhoso. M as pensar que sua energia é imensa. 0 IN CA tem uma força enorme e pode contribuir muito para as mudanças. Temos que ter mais compromisso com a solução.

\section{Elton Leme}

0 debate é salutar e o conflito possibilita um grande crescimento social, e esta Jornada é um exemplo disso.

\section{Bibliografia sugerida}

KOTTOW, M. Introduccíon a la bioética. Santiago: Editorial U niversitária. 1995.

SIN GER, P. Ética Prática. São Paulo: Martins Fontes, 1994. 399p. 